ISSN 0258-7122

Bangladesh J. Agril. Res. 40(1): 95-108, March 2015

\title{
CONSTRAINTS AND SUGGESTIONS FOR MODERN VARIETY POTATO PRODUCTION TECHNOLOGY
}

\author{
A. B. M. SHARIF UdDIN ${ }^{1}$, M. MOSTAFIZUR RAHMAN ${ }^{2}$, M. HASANUL KABIR \\ KAMALY $^{3}$, M. BASHIRUL ALAM ${ }^{4}$ AND M. MOHIUDDIN SHEIKH ${ }^{5}$
}

\begin{abstract}
A study was carried out to determine the production constraints of modern varieties of potatoes and also find out the probable suggestions to overcome the constraints as verified the views between the farmers and extension officials. Data were collected from 232 farmers sampled randomly from 1547 potato growers and 51 extension officials from 153 population available from the study area of three upazila namely; Durgapur, Mohanpur and Bagmara under Rajshahi district of northwest area of Bangladesh. The study area was selected through multistage sampling procedure with continuous field observation and consultations with teachers, extension personnel, experts and contact farmers along with literatures reviewed. Thus, twenty important constraints regarding potato production were identified and possible suggestions for overcoming the constraints were suggested by using the same procedure. The importance of the constraints and the suggestions were measured by using 'Important Constraints Score Index (IPSI)' and 'Important Suggestion Index (ISSI)'. Out of 20 constraints and suggestions views of farmers and officials differed significantly for 15 items and 13 items.
\end{abstract}

Keywords: Constraints, suggestions, potato production.

\section{Introduction}

The potato refers to starchy tubers produced under soil from the crop plant Solanum tuberosum L. of the botanical family Solanaceae ranks among the four most important food crops in the world including wheat, rice and corn (VanDiepan, 2003). Potato is the third most important crop of Bangladesh followed by rice and wheat. It is commonly used as vegetables and contributes 63 percent of the total annual vegetable production in Bangladesh (BBS, 2008). Bangladesh has made a reasonable progress in potato production during 1950-51 to 2011-12. Area and production under potato has increased to double during the same period due to favorable soil and climate. In general, potato takes 90 to 115 days for maturity but early variety potato could be harvested after 75 days of plantation. Bangladesh has good potential to produce potato yields more than 30 ton per

${ }^{1}$ Chief Executive Officer, Zila Parishad, Natore, ${ }^{2}$ Professor, Department of Agronomy and Agricultural Extension, University of Rajshahi, Rajshahi-6205, ${ }^{3}$ Upazilla Agriculture Officer, Tanore, Rajshahi, ${ }^{4}$ Chief Estate Officer, Bangladesh Railway (West), Rajshahi and ${ }^{5}$ Scientific Officer, Bangladesh Agricultural Research Institute (BARI), Breeder Seed Production Centre, Debigonj, Panchagarh, Bangladesh. 
hectare but actual yield is around 19.07 tons per hectare in 2012 (The Financial Express, 2013). Potato is ideally suited to places where land is limited and labour is abundant. Moreover, the potato is a highly productive crop which produces more food per unit area and per unit time than cereal crops. The factors that influence potato yield and quality includes cultivar, soil type, weather conditions, water management, fertilization, plant population, seed size, pests and diseases. The potato gives a high return compared to other crops in Bangladesh and it is cultivated during the Rabi season from November to February. The selection of high yielding varieties along with other production factors plays an important role to increase the yield per unit area (Khan, 2009). With access to production inputs, continued expansion in post harvest support in the form of roads and cold storages in the country, farmers continue to find potatoes an extremely attractive crop to grow. To accelerate potato production, the present study was undertaken with the objectives:

I. Determine the chronology of important potato production constraints and depict the priority of important suggestions and

II. Compare the significant relationship of views between farmers and extension officials.

\section{Materials and Method}

Modern variety potato farming is done in almost all agricultural zones of Bangladesh either in large or in a small scale. The researcher considered mainly two varieties namely Cardinal and Diamont as modern potato varieties for the study area due to their seed availability, production nature and market demand than others like Hira, Dhira, Chamak, Kufri Sindhuri, Granola etc. But as a potential area in northwest Bangladesh the study was conducted with randomly selected twenty villages in four unions of three upazilas (Durgapur, Mohanpur and Bagmara) under Rajshahi district. Out of available 1547 potato farmers a sample of $15 \%$ of them (232) was selected by using a Table of Random numbers (Kerlinger, 1973) and another second group of 15\% extension personnel (51) were selected from the study area and 51 extension officials were interviewed for the constraints of potato production with possible suggestions for overcoming the constraints by the same questions as prepared in interview schedule for the farmers. A four point of awareness scale was prepared in this study for measuring potato production constraints of the farmers. Initially 24 statements were prepared and carefully examined by extension experts and their existence in the study area was also checked by farmers outside the study respondents during pre-testing of interview schedule. Out of 24 statements, 20 were selected as their existence more or less prevailing in the study area. To determine the degree of consideration a four point of awareness scale is set up against each selected constraint. Data were collected during the month of July 2010 to February 2011. 
Necessary secondary data were also collected from different sources in addition to primary data.

\section{Measurement of the importance of constraints in potato production}

Extent or importance of each constraint in potato production as opined either by the farmers or by the agricultural extension officials was computed. The respondents of the study area pointed out the extent of different constraints by putting a tick mark in any one of four columns such as very important (extreme), important (high), moderate (medium) and less important (low). These responses were quantified by assigning weights very important, important, moderately important and less important as 4, 3,2 and 1.

The important score was computed for each constraint by summing the weights for responses of the respondents against that constraint. For easy understanding of the constraint, the importance score (IS) of each of the constraint was computed and was expressed in percentage by using the following formula: IS = $\mathrm{Pvh} \times 4+\mathrm{Ph} \times 3+\mathrm{Pm} \times 2+\mathrm{Pl} \times 1$ and

Important Constraint Score Index $($ ICSI $)=\frac{\text { Observed ConstraintScore }}{\text { Possible ConstrainScore }} \times 100$

The possible important constraint score index (ICSI) of a constraint could range from 232 to 928 , where 232 indicated that the statement is less important as a constraint in potato production, while 928 indicated very high constraint faced by the farmers in the cultivation of potato.

\section{Measurement of the importance of suggestions in potato production}

In respect of each suggestion, the respondents indicated importance of solutions/suggestions by putting a tick mark in any one of four responses such as very important (extreme), important (high), moderate (medium) and less important (low). These responses were quantified by assigning weights very important, important, moderately important and less important as 4, 3, 2 and 1.

The important score (IS) of solutions/suggestions were computed by summing the weights for responses of the respondents. Therefore, the importance score of solution/suggestion could range from 232 to 928 for farmers while it could range from 51 to 204 for officers. For easy understanding, the importance score (IS) of each of the solution/suggestion was computed and expressed in percentage by using the following formula:

Important Solution Score Index (ISSI) $=\frac{\text { Observed Solution Score }}{\text { Possible Solution Score }} \times 100$ 
Where zero indicated no important suggestion for encouraging the production of potato and 100 indicated very high encouraging suggestion for practicing technologies in potato cultivation by the farmers i.e. higher the ISSI, the higher was the solution important for practicing improved technologies in potato cultivation.

Comparing the means of constraints of potato production by two independent groups of farmers and extension officials, $t$-test was used.

The ratio $=\frac{\text { difference }}{\text { standarderrorof difference }}$

When, the standard error of difference is estimated from the sample is denoted by t. $t$-test is used for small samples, as $t$-distribution tends to be normal distribution when $d f$ is greater than 30 (in this case 50 and 231).

$\mathrm{t}$ is calculated by the formula,

$$
\begin{aligned}
& \mathrm{t}=\frac{\overline{x_{1}}-\overline{x_{2}}}{S \sqrt{\frac{1}{n_{1}}+1 / n_{2}}} \text { at } \mathrm{n}_{1}+\mathrm{n}_{2}-2 \mathrm{df} \\
& \mathrm{S}=\sqrt{\frac{\left(n_{1}-1\right) S_{1}^{2}+\left(n_{2}-1\right) S_{2}^{2}}{n_{1}+n_{2}-2}}
\end{aligned}
$$

Where, $\bar{x}_{1}=$ mean of first sample (farmers); $\bar{x}_{2}=$ mean of second sample (officials); $\mathrm{n}_{1}=$ number of observation in first sample; $\mathrm{n}_{2}=$ number of observation in second sample

\section{Results and Discussion}

Constraints in potato production as perceived by the farmers and extension officials

It was assumed that the views of farmers may differ with that of agricultural personnel regarding importance of constraints in potato production. As such cross check the matter between end user of potato technologies and extension service provider concerned with the technologies were recorded. The constraints with rank order as opined by the farmers are presented in Table 1.

\section{Comparative analysis of constraints}

From the rank orders of farmers and officials it has been seen that the views are not same and the degree of importance given by scoring also differed from one another. Important Constraints Index Score (ICIS) as obtained from farmers 
ranged from 42.24 to 90.30 and ICIS from officials ranged from 51.47 to 69.11 percent. The constraints range of farmers is much more than that of officers and the second category of opinion (Important, weight as assigned 3) ranked the top in total score from both type of respondents. Farmers opined low or less important category as last grade while officials opined very important category as last grade. Mostly farmers of Bangladesh are subsistence and they always try to ensure their food production only for survival. But they cultivate some cash crops for their economic gain as to meet cost involvement in agriculture and to ensure food security by increasing own capital. Potato is one of the leading cash crop, requires initial high investment for its production. The market price is observed low during harvesting season but it is unwise to store at home due to rapid decomposition. On the other hand, potato is not procured by the Government like other crops (rice and wheat) which create the frustration to the growers. This scenario ultimately shows a fall of law of diminishing returns of economic analysis. To protect the crop, in case of seed, good care is required which lead to need enough money. The most important constraints for farmers' ranked as 1, 2, 3 and 4, respectively i.e. initial investment high, lack of Govt. procurement, storing cost at cold storages and low market price of potato. The concerned officials opined that lack of Govt. procurement, storing cost at cold storages, lack of information and high price of pesticides is ranked 1, 2, 3 and 4 accordingly. From the both group of respondents it has been found that each group had given prime concern of cost involvement as the leading constraint of potato production. Other constraints have also ranked by them with their views but the degree of importance and ranking differs distinctly. From the above observations it has been thought to proceed for looking into the consistency or inconsistency for evaluating the difference statistically by $t$-test. Out of 20 constraints it was found that views of farmers and officers differed insignificantly only for 5 items and the rest 15 differed significantly. Insignificant difference of five constraints are storing cost at cold storage, low market price of potato, lack of timely quality seed supply, lack of seed cold storage and high price of pesticides. Most of cold storage are private enterprise and their regulation or operation are not controlled by extension departments and all the potato growers are supposed to admit either high price rate/bag at cold storage or to sell their produce at low price immediately after harvesting. No alternative option for farmers or no liability of the extension department to procure potato like rice or wheat as done by food department. So neither farmer nor extension officials might claim each other regarding the remarking situation which creates same perception of these two constraints. Not more than $10 \%$ of total seed demand is met by the Government agency BADC whole to fulfill the rest amount farmers have to run towards different companies or persons to get the quality seed. Though their field is ready in time to plant tuber but deviation due to seed supply situation. As this reality 


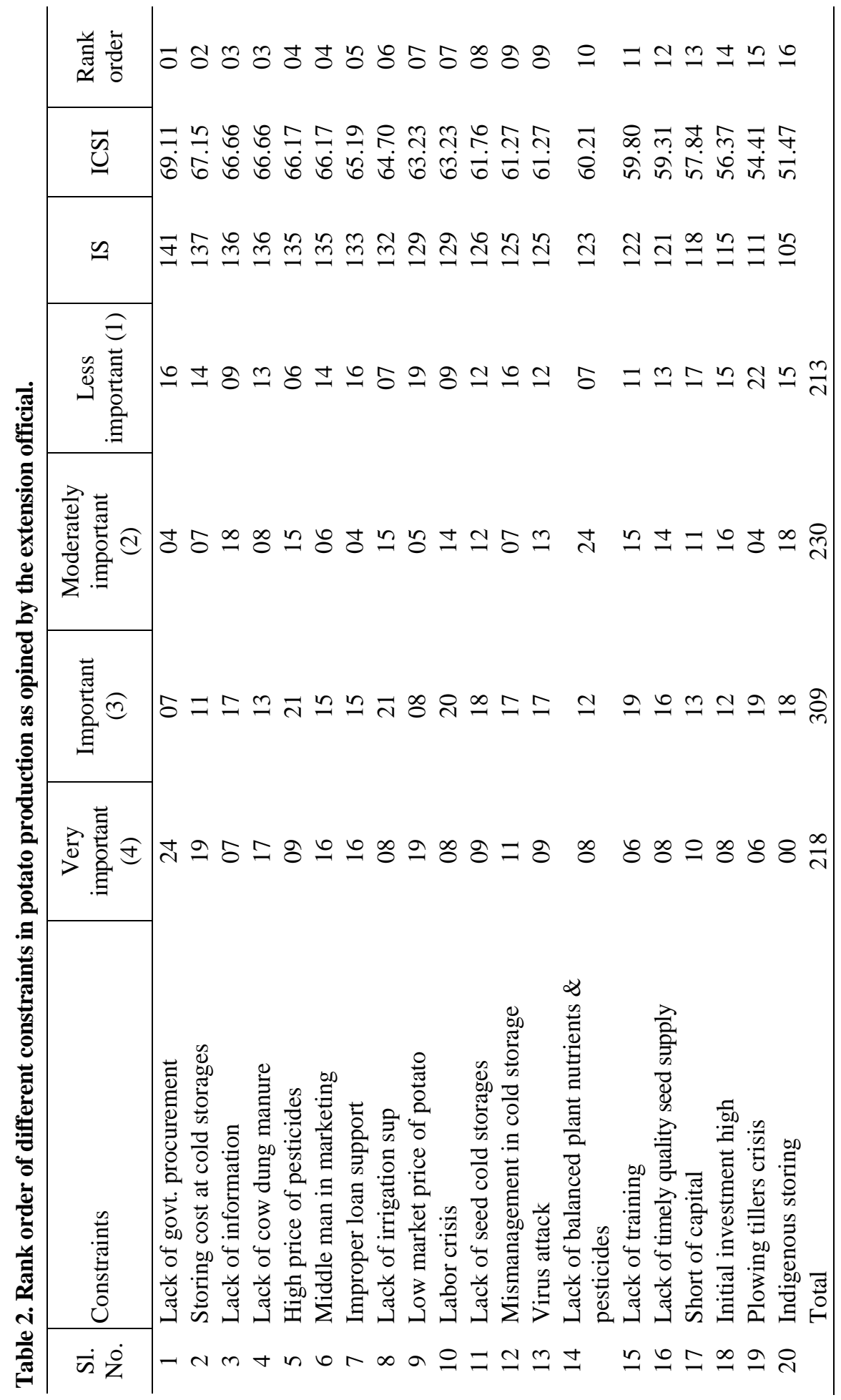




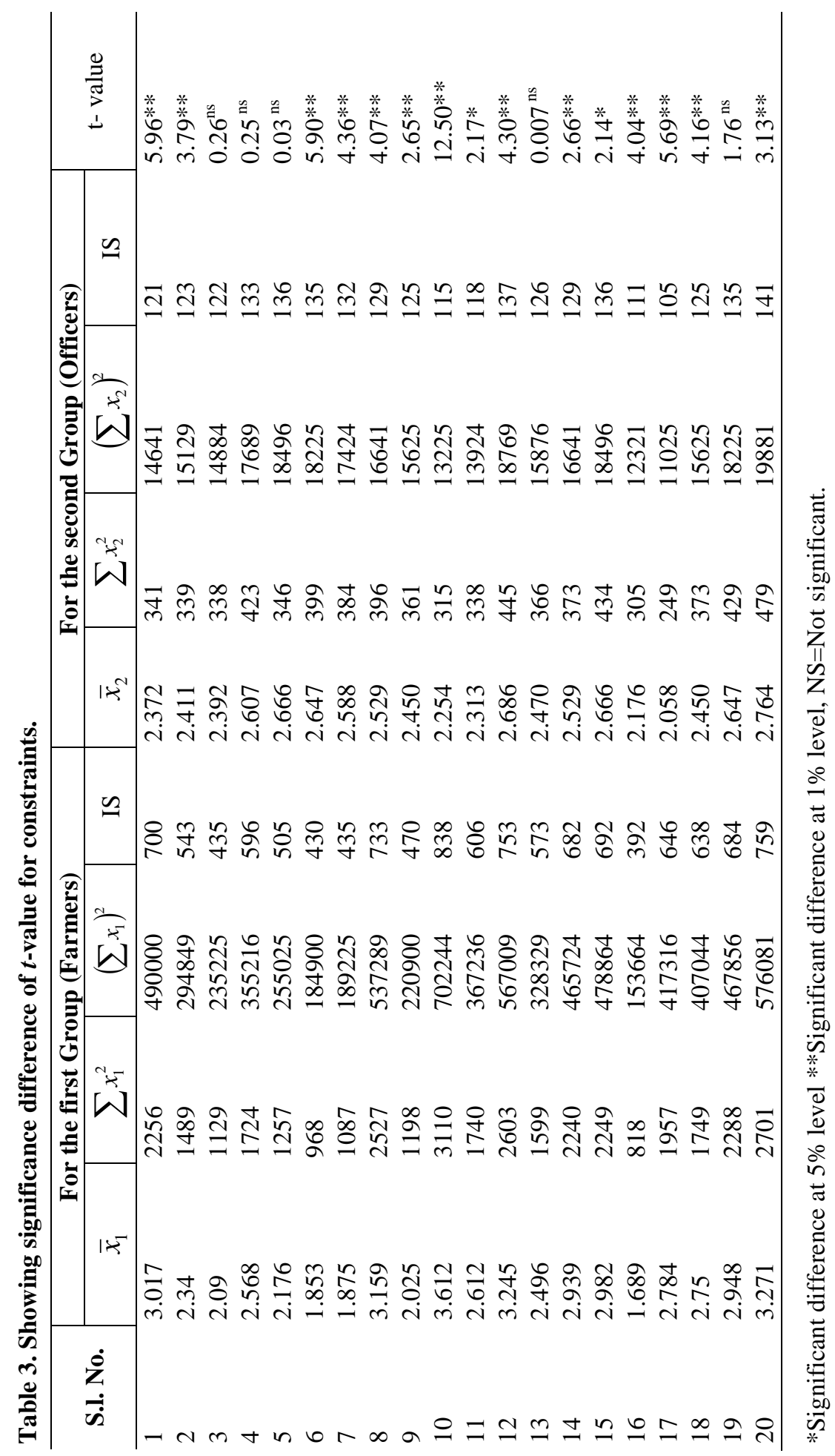


might not be overcome so no scope of difference in opinion. Numbers of cold storage are available to preserve potato for table purpose but specialized cold storages only for storing seed is very hardly found. This is why, both farmers and officials are of the same opinion. Due to situational demand like foggy weather quickly support predisposition for late blight of potato. To prevent such attack, fungicides demand increases very rapidly, then the chance of higher price is a country picture of general experience display the same situational opinion by the farmers and extension officials.

\section{Suggestions for overcoming the constraints in potato production}

Transfer of technology is meaningless until the technology is adopted by the potential farmers. Attributes of production technologies are considered very important to play a crucial (positive or negative) role for perceiveness towards a technology. An attempt was made to find out the relevant suggestions/solutions for overcoming the constraints in using technologies of potato cultivation. The means of suggestions to overcome the constraints of potato production of two independent groups (farmers and officers) are calculated as followed earlier (for comparing the means of solutions as given by the respondent potato farmers and officers of agricultural extension by $t$-test). The solution/suggestion with rank order as opined by the respondent farmers and officers are presented in Table 4 and 5. If there is permanent procurement system by the Government, farmers are not loosed from the potato production. This is why the suggestion of initiative of Government procurement was come from the farmers as first rank basis. Also production is mainly depended on timely input supply. In potato season, farmers have to move here and there to buy or collect the inputs. Sometimes they are misguided or not get quality input. Day by day the storing cost is increasing. In harvesting time, the price is very low. It is common culture in Bangladesh and potato growers are suffering. Also due to shortage of cold storage they have to sell potato with low price. Farmers feel to need advance training on potato cultivation. With consider to the above field situation, the rank wise (2, 3, 4 and 4) important suggestions by the farmers were input supply, reducing storing cost, price fixation at harvesting period and arranging training. On the other hand, the five important suggestions by the officers to overcome the constraints are in the following order: (i) easy loan support, (ii) cattle farming for manure, (iii) reducing storing cost, (iv) co-operative marketing and (v) reducing price of pesticides. From the rank orders of farmers and officials it has been seen that the views are not same and the degree of importance of suggestions given by scoring also differed from one another. Calculated values are placed in Table 6 for showing significance difference of $t$-value. Out of twenty items of suggestions, seven items have been found to differ insignificantly between two independent groups of respondents but the rest thirteen differed significantly. It might be due to unconsciousness or concealing tendency towards field level limitations 


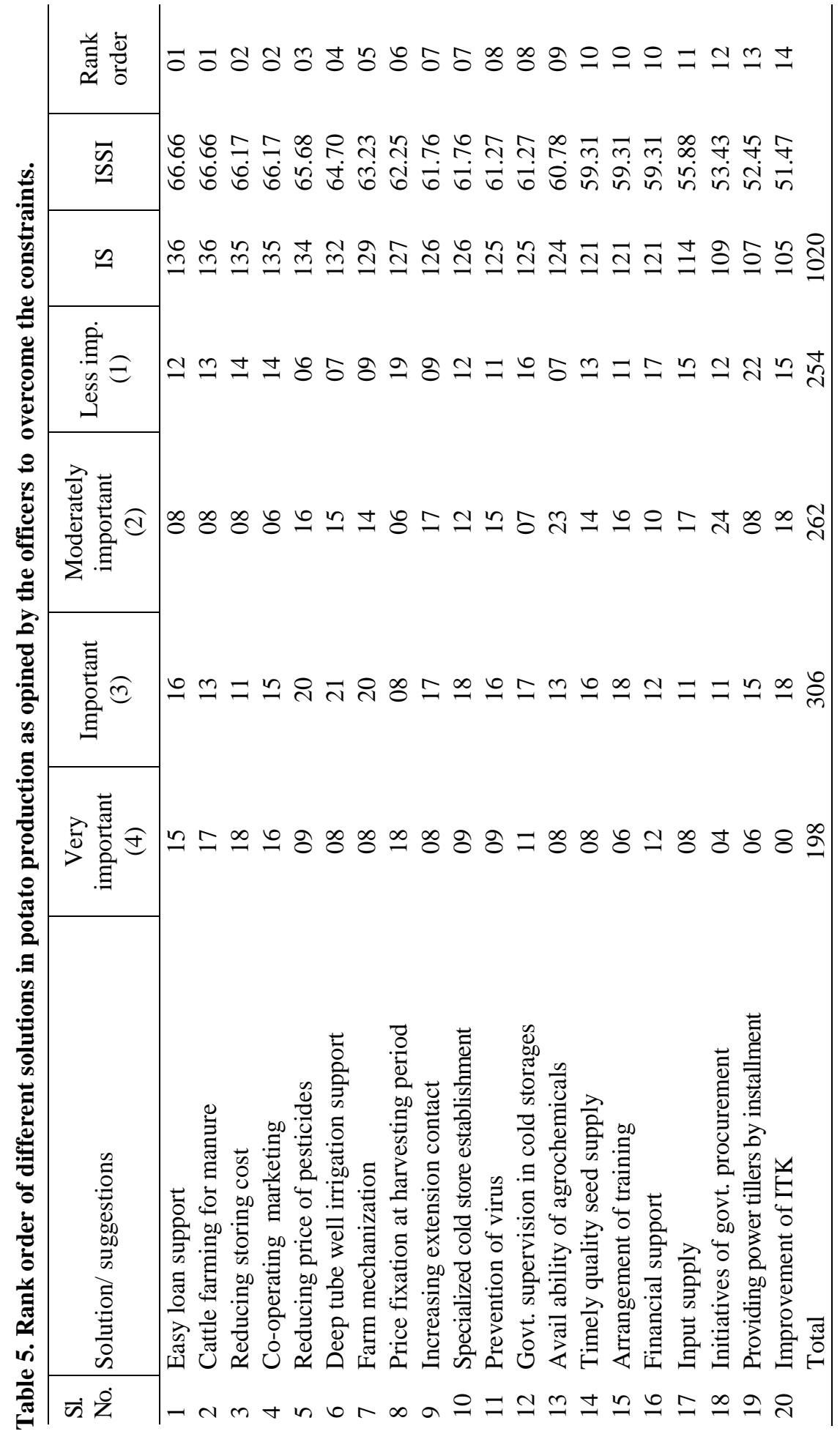




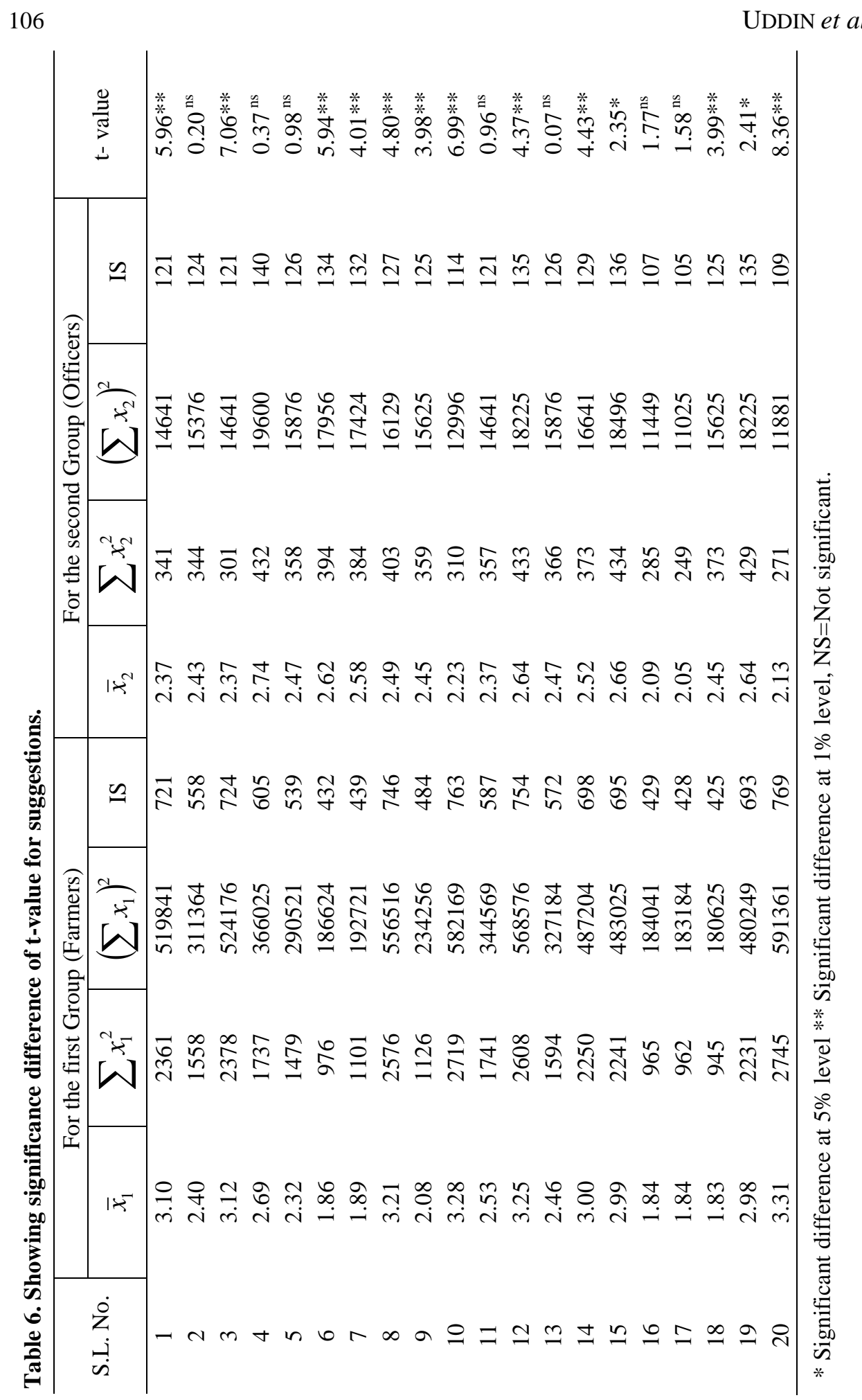


followed by giving as usual progress report to the higher authorities to get recognition of better performance. On the other hand, field level suggestions by the incumbents or end users (farmers) don't consider the limitation of resources but expect subsidy or free support from the Government departments. The situational position of the respondents may draw different degree of importance but do not show unimportance. So combined evaluation of responses is being considered urgent in this regard to increase production of potato.

\section{Conclusion}

The most important constraints reported by the farmers and officials ranked in the following order: (i) high initial investment, (ii) lack of Government procurement, (iii) storing cost high at cold storage, (iv) low market price of potato, (v) lack of timely quality seed supply, (vi) lack of cow dung manure and (vii) high price of pesticides. Similarly top ranking of suggestions by farmers and officials (i) initiatives of Govt. procurement, (ii) timely input supply, (iii) reducing storing cost, (iv) price fixation at harvesting level, (v) arrangement of modern method of production training, (vi) easy loan support, (vii) co-operative marketing and (viii) reducing price of pesticides. Out of 20 constraints, it was found that views of farmers and officials differed insignificantly only for 5 items. In case of suggestions, seven items have been found to differ insignificantly between two independent groups of respondents but the rest thirteen differed significantly. It might be due to unconsciousness or concealing tendency towards field level limitations followed by giving as usual progress report to the higher authorities to get recognition of better performance. On the other hand, field level suggestions by the incumbents or end users (farmers) don't consider the limitation of resources but expect subsidy or free support from the Government departments. The situational position of the respondents may draw different degree of importance but do not show unimportance. Modern variety potato production technology is a complex matter and it is considered with different aspects. If a farmer follows all aspect in his field he can get more production. So combined evaluation of responses is being considered urgent in this regard to increase production of potato. To improve and ensure the maximum production, the attitude of growers and service provider should possess same views in spite of significant difference.

\section{References}

BBS, 2008. Monthly Statistical Bulletin of Bangladesh, October, 2008. Bangladesh Bureau of Statistics, Statistics Division, Ministry of Planning, Government of the People's Republic of Bangladesh.

Khan, A. B. M. 2009. A Study on the Performance of Different USA Potato Lines. M.S. Thesis. Department of Horticulture, Bangladesh Agricultural University, Mymensingh, Bangladesh. 
Kerlinger, F. N. 1973. Foundations of Behavioral Research: Educational and Psychological Inquiry. 2nd Ed. New York: Holt, Rinchart and Winston, Inc.

Rashid, M. M. 1987. Potato Production in Bangladesh. A Consultancy Report Prepared for FAO Regional Office for Asia and the Pacific, Bangkok, Thailand. Tuber Crops Research Center, Bangladesh Agricultural Research Institute, Joydebpur, Gazipur, Bangladesh.

The Financial Express (Daily Newspaper). 2013. Dated $5^{\text {th }}$ September, Page No.8.

Van-Diepan, M. R. (ed.). 2003. Netherlands Catalogue of Potato varieties, NIVAP, The Netherlands. 